\title{
Protein Synthesis, Cell Division and the Cell Cycle in Saccharomyces cerevisiae following a Shift to a Richer Medium
}

\author{
By B. L. A. CARTER AND A. LORINCZ \\ Department of Genetics, Trinity College, University of Dublin, \\ Dublin 2, Ireland \\ AND G. C. JOHNSTON \\ Department of Microbiology, Dalhousie University, Halifax, Nova Scotia, Canada
}

(Received 5 December 1977)

\begin{abstract}
When both haploid and diploid cells of the yeast Saccharomyces cerevisiae were shifted to media supporting faster growth rates, rate maintenance of cell division was observed. Both protein synthesis and cell division displayed a variable period of rate maintenance prior to achieving new rates after shift-up; however, the interval between the increase in rate of protein synthesis and the increase in rate of cell division remained constant. These results are consistent with a model of the cell division cycle in which there is an expandable G1 phase during which growth to some critical size must be attained. Once cell division cycle events are initiated they proceed at a constant rate regardless of the overall population growth rate.
\end{abstract}

\section{INTRODUCTION}

Kjeldgaard, Maaløe \& Schaechter (1958) observed that when cells of Salmonella typhimurium were shifted to a richer medium, cell division continued at the pre-shift rate for $60 \mathrm{~min}$ and then abruptly assumed the rate characteristic of the richer medium. This phenomenon of rate maintenance of cell division was explained by the model of Cooper \& Helmstetter (1968) in which the period from initiation of DNA synthesis to cell division is constant for cells growing at different rates in different media. The increased rate of cell division after the shift is due to an increased rate of initiation of DNA replication. After a shift-up this increased rate of cell division will not be manifest until a time equal to the interval between initiation of DNA replication and cell division.

Here we report that when the yeast Saccharomyces cerevisiae was shifted to richer medium, rate maintenance of cell division occurred for $120 \mathrm{~min}$ after the rate of protein synthesis shifted to the higher value characteristic of the richer medium. The rate of cell division then increased abruptly to the new rate.

These findings can be interpreted to suggest that the yeast cell cycle is similar to that of bacteria in that, at a variety of growth rates, there is a period of the cell cycle of constant duration prior to cell division. Implications of this observation for control of cell cycle initiation are discussed.

\section{METHODS}

Strains and media. Saccharomyces cerevisiae strain A364a/a ade1 ade2 ura1 his7 lys 2 gal1 and the prototrophic diploid c276 were employed. The media used were YEPD, YEPG and YNB which have been described previously (Hartwell, 1970; Johnston, Pringle \& Hartwell, 1977). Proline minimal medium (PMM) contained $0 \cdot 1 \%(\mathrm{w} / \mathrm{v})$ proline, $2 \%(\mathrm{w} / \mathrm{v})$ glucose and $0 \cdot 14 \%(\mathrm{w} / \mathrm{v})$ yeast nitrogen base without amino acids; and ethanol minimal medium (EMM) contained $2 \%(\mathrm{v} / \mathrm{v})$ ethanol, $0.5 \%(\mathrm{w} / \mathrm{v})$ ammonium sulphate 
and $0.67 \%(w / v)$ yeast nitrogen base without amino acids. For growth of $A 364 a$, minimal media also contained (per litre) $0.04 \mathrm{~g}$ tyrosine, $0.04 \mathrm{~g}$ lysine, $0.04 \mathrm{~g}$ histidine, $0.01 \mathrm{~g}$ uracil and $0.01 \mathrm{~g}$ adenine, plus trace elements and vitamins. Cultures were grown on rotary shakers at room temperature.

Cells were shifted to richer media by dilution into medium supporting faster growth.

Samples for cell number determinations were treated as previously described (Hartwell, 1970). Cell numbers were determined using an electronic particle counter (Coulter Electronics, Dunstable, Bedfordshire). Samples for total protein analysis were treated as described previously (Johnston et al., 1977).

\section{RESULTS}

Shift-up to rich medium at $24^{\circ} \mathrm{C}$

When yeast cells of strain A364a grown in PMM medium (mass doubling time, $260 \mathrm{~min}$ ) were shifted by dilution into YEPD medium, the rate of protein synthesis increased almost immediately to the new value (mass doubling time, $170 \mathrm{~min}$ ) (Fig. 1). The rate of cell division remained at the pre-shift value for $130 \mathrm{~min}$ before assuming the value characteristic of the richer medium (Fig. 1).

After a shift from YEPG medium, capable of supporting a mass doubling time of $280 \mathrm{~min}$, to YEPD medium, protein synthesis continued at the pre-shift rate for $70 \mathrm{~min}$ before increasing to the new rate (mass doubling time, $150 \mathrm{~min}$ ) (Fig. 2). The rate of cell division continued at the pre-shift rate for $190 \mathrm{~min}$ before increasing to the value characteristic of the post-shift medium (Fig. 2). It should be noted that, as with the shift from PMM to YEPD medium, transferring cells from YEPG to YEPD only resulted in an increased rate of cell division $120 \mathrm{~min}$ after the rate of protein synthesis increased.

Yeast cells grow with a mass doubling time of 425 min in EMM medium. When such cells were shifted by dilution into YEPD medium, protein synthesis continued at the preshift rate for $120 \mathrm{~min}$ before its rate increased to a mass doubling time of $150 \mathrm{~min}$ (Fig. 3). The rate of cell division continued at the pre-shift rate for $240 \mathrm{~min}$ before abruptly changing to the new rate. Again, the interval between the change in the rate of protein synthesis and the change in the rate of cell division was $120 \mathrm{~min}$, similar to that observed in the shift from PMM to YEPD.

Medium shift experiments were also performed with the prototrophic diploid strain C276. In this case, cells were grown in YNB with acetate as carbon source, then shifted to YNB medium containing glucose. In acetate, cells had a mass doubling time of $420 \mathrm{~min}$. After the medium shift there was a lag of 165 min before protein synthesis assumed the new, faster rate (mass doubling time, $120 \mathrm{~min}$ ) (Fig. 4). As found with the haploid strain A364a, the rate of cell division did not increase until about $120 \mathrm{~min}$ after the change in rate of protein synthesis. Similar results were obtained when cells of strain c276 were shifted from YEPG to YEPD or from YNB containing leucine as sole nitrogen source to YNB containing ammonium sulphate as a nitrogen source (data not shown).

\section{DISCUSSION}

Our main interest in starting this work was to investigate the effects of shifts from poor media to rich media on the rate of cell division. We report that yeast, like Escherichia coli (Cooper, 1969), exhibited the phenomenon of rate maintenance after shifts to rich media as suggested by earlier observations of Jacobson \& Parks (1973). Both the rate of protein synthesis and the rate of cell division were maintained at pre-shift values before increasing rather abruptly to higher rates. The length of time that protein synthesis remained at the pre-shift rate was dependent on the growth rate of cells at the time of the shift. For instance, for cells growing with a mass doubling time of $260 \mathrm{~min}$ the rate"of protein synthesis changed almost immediately to the new value after the medium shift, while for cells growing with a mass doubling time of $425 \mathrm{~min}$, protein synthesis remained at the pre-shift value for $120 \mathrm{~min}$ before increasing. The duration of rate maintenance of cell division after a shift was also 

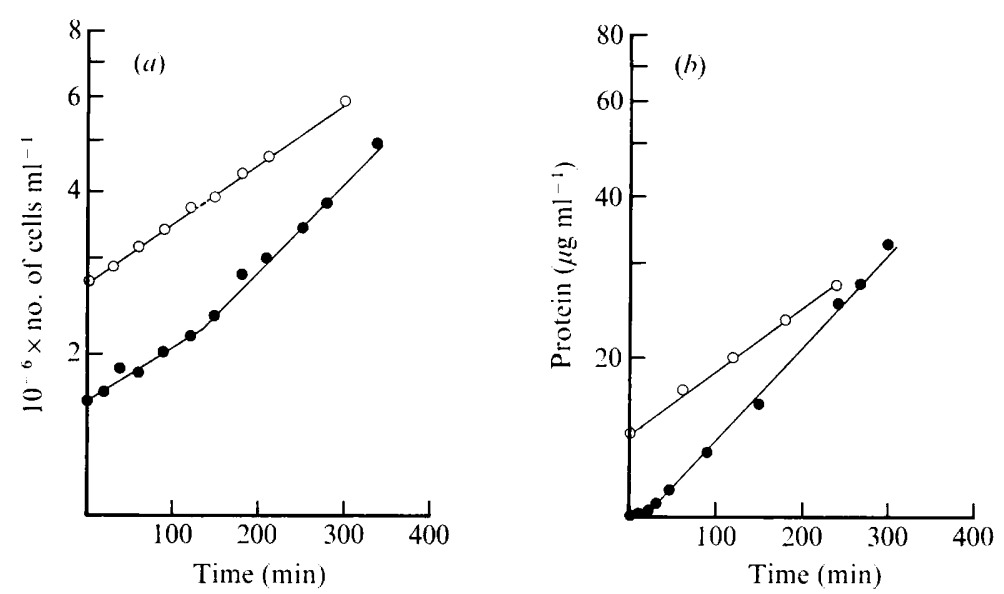

Fig. 1. Effect of shift-up on protein synthesis and cell division in cells of $S$. cerevisiae strain A364a. At zero time, cells growing exponentially in PMM medium were transferred to either PMM (O) or YEPD medium (O). At intervals, samples for cell number and protein determinations were taken as described in Methods: $(a)$ cell number increase after shift-up; $(b)$ protein accumulation after shift-up.
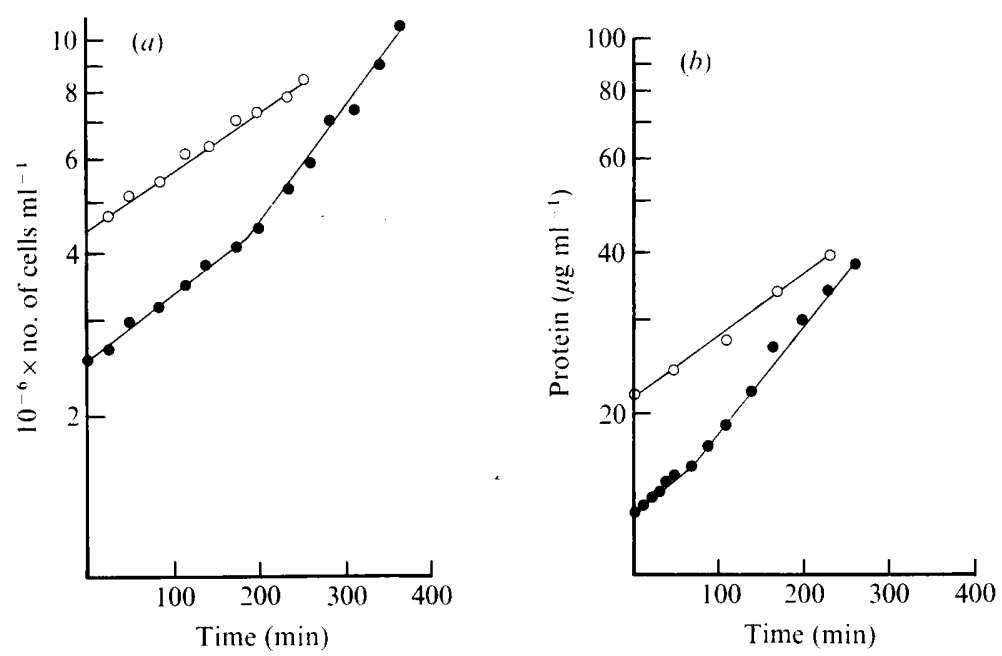

Fig. 2. Effect of shift-up on protein synthesis and cell division in cells of S. cerevisiae strain A364a. At zero time, cells growing exponentially in YEPG medium were shifted to either YEPG medium $(\bigcirc)$ or YEPD medium (O). At intervals, samples for cell number and protein determinations were taken as described in Methods: $(a)$ cell number increase after shift-up; $(b)$ protein accumulation after shift-up.

dependent on the pre-shift growth rate. When allowance is made for the fact that the preshift rate of protein synthesis was maintained for a period dependent on the pre-shift mass doubling time, it is apparent that in all cases cell division continued at the pre-shift rate for about 120 min after the rate of protein synthesis increased and then itself increased rather abruptly. Thus there is within the yeast cell cycle a period which is of constant duration regardless of growth rate.

Recent studies with the yeast $S$. cerevisiae (Jagadish \& Carter, 1977) suggest that the cell cycle of this organism can be subdivided into phases of variable and constant duration. As the growth rate slows, the G1 portion of the cell cycle, from cell division to initiation of 

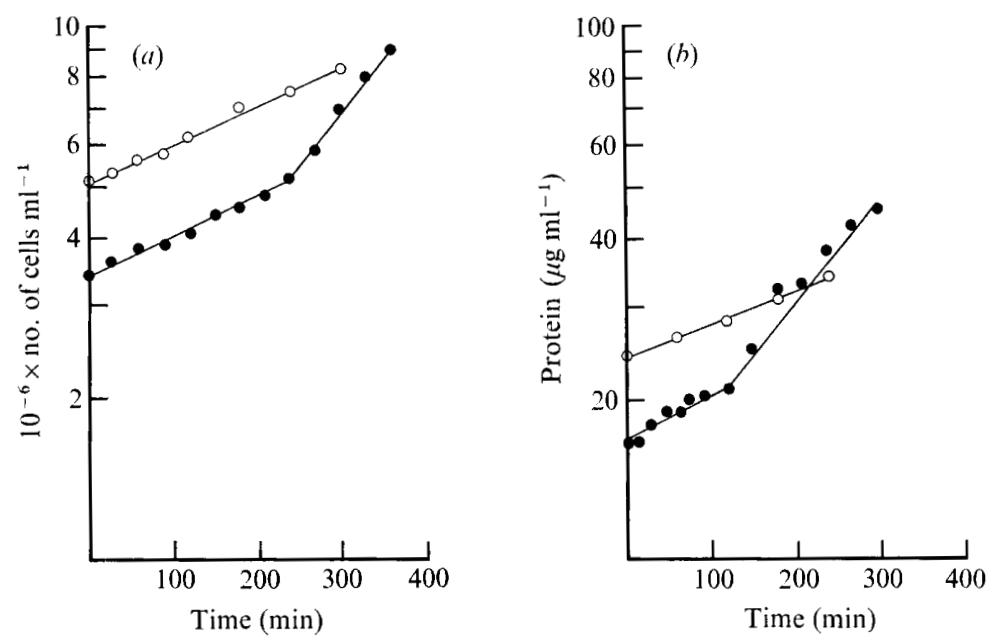

Fig. 3. Effect of shift-up on protein synthesis and cell division in cells of $S$. cerevisiae strain A364a. At zero time, cells growing exponentially in EMM medium were shifted to either EMM medium (O) or YEPD medium (O). At intervals, samples for cell number and protein determinations were taken as described in Methods: $(a)$ cell number increase after shift-up; $(b)$ protein accumulation after shift-up.
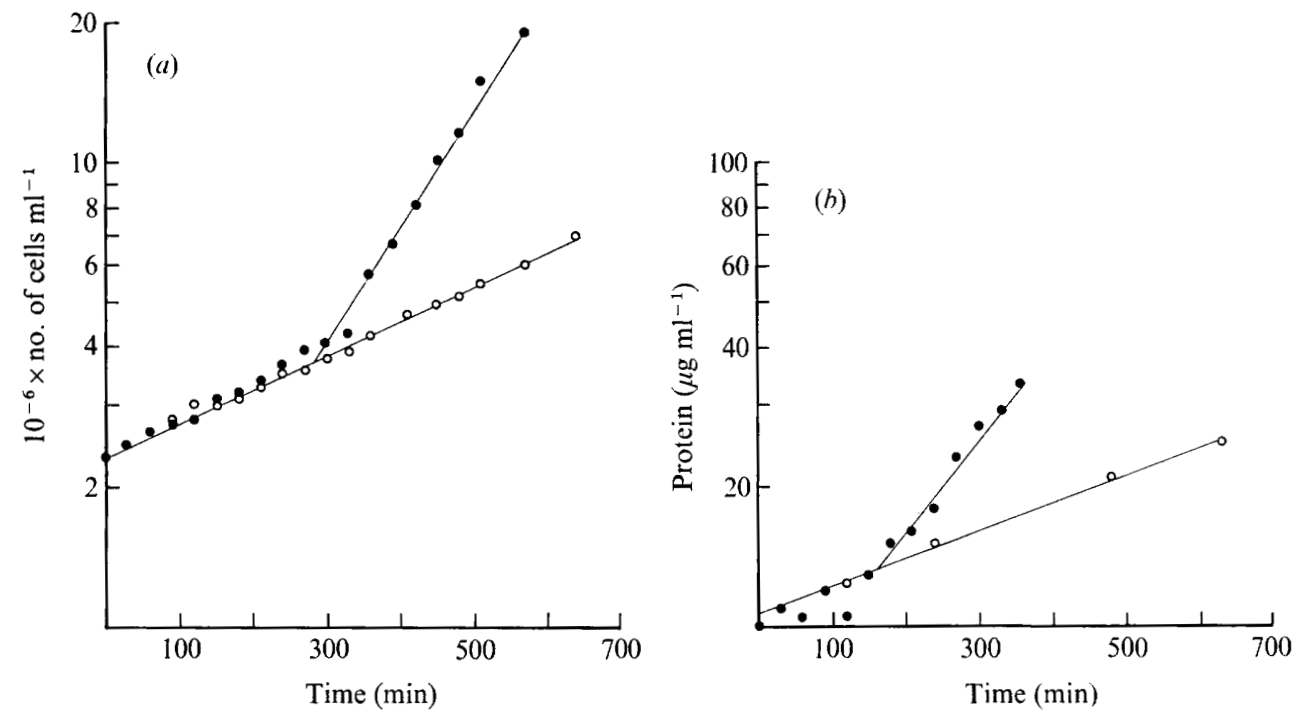

Fig. 4. Effect of shift-up on protein synthesis and cell division in cells of $S$. cerevisiae strain $\mathrm{C} 276$. At zero time, cells growing exponentially in YNB medium with acetate as carbon source were shifted to either YNB medium with acetate as carbon source $(O)$ or YNB medium with glucose as carbon source (O). At intervals, samples for cell number and protein determinations were taken as described in Methods: $(a)$ cell number increase after shift-up; $(b)$ protein accumulation after shift-up.

DNA replication, is extended. However, at growth rates varying from 2 to $7 \mathrm{~h}$, there is a constant period, from the initiation of DNA synthesis to cell division, independent of growth rate.

If the period from initiation of DNA synthesis to cell division is constant at a variety of growth rates, then after a shift to rich medium the rate of cell division will not increase for a period equal to this constant phase. As we have suggested (Johnston et al., 1977), growth 
to some critical size is rate-limiting for initiation of DNA synthesis and entrance into this constant phase. One measure of growth is protein synthesis; once a new increased rate of protein synthesis is established, cells enter the constant phase of a cell cycle at an increased rate. This is reflected in an increased rate of cell division 120 min later.

These data are consistent with a model of cell division for $S$. cerevisiae in which there is both an expandable phase (in which growth is rate limiting) and a constant phase (in which growth is not rate limiting).

In a parallel study with the fission yeast Schizosaccharomyces pombe, Fantes \& Nurse (1977) observed that when cells were shifted from a poor medium to a rich medium the rate of protein synthesis increased from the old to the new value within minutes of the shift. Almost immediately the rate of cell division increased to a higher rate than the pre-shift value. Cell division then stopped for a period before resuming at a higher rate than the preshift value. Clearly the response of the fission yeast to a shift to richer medium is different from that of the budding yeast $S$. cerevisiae. Fantes \& Nurse (1977) observed that one of the first effects of the shift is a complete but transient inhibition of nuclear division. They postulate on the basis of their results and earlier work by Nurse (1975) that there is in the fission yeast a cell size requirement for entry into nuclear division and that the cell size necessary for nuclear division is set or modulated by the prevailing growth conditions. The apparent differences in the control of cell division in these two yeasts warns against extrapolation of control models to other eukaryotes.

B.L.A.C. would like to thank Trinity College, Dublin, for the provision of a special grant to purchase a Coulter Channelizer. B.L.A.C. was supported by the Medical Research Council of Ireland and Arthur Guinness Son \& Co. Ltd, and by NATO Grant 1148. G.C.J. was supported by the Medical Research Council of Canada Grant MA5776. G.C.J. also wishes to thank Dr R. Singer for helpful discussions.

\section{REFERENCES}

COOPER, S. (1969). Cell division and DNA replication following a shift to a richer medium. Journal of Molecular Biology 43, 1-11.

COOPer, S. \& Helmstetter, C. E. (1968). Chromosome replication and the division cycle of Escherichia coli B/R. Journal of Molecular Biology 31, 519-540.

Fantes, P. \& Nurse, P. (1977). Control of cell size at division in fission yeast by a growth-modulated size control over nuclear division. Experimental Cell Research 107, 377-386.

Hartwell, L. H. (1970). Periodic density fluctuations during the yeast cell cycle and the selection of synchronous cultures. Journal of Bacteriology 104, 1280-1285.

Jacobson, G. K. \& Parks, L. W. (1973). Cell division and deoxyribonucleic acid synthesis after a nutritional shift-up of Saccharomyces cerevisiae. Journal of Bacteriology 114, 876-877.

JAGADISH, M. N. \& CARTER, B. L. A. (1977). Genetic control of cell division in yeast cultured at different growth rates. Nature, London 269, 145-147.

Johnston, G. C., Pringle, J. R. \& Hartwell, J. H. (1977). Coordination of growth with cell division in the yeast Saccharomyces cerevisiae. Experimental Cell Research 105, 79-98.

KJeldgaArd, N. O., MaAløe, O. \& Schaechter, M. (1958). The transition between different physiological states during balanced growth of Salmonella typhimurium. Journal of General Microbiology 19, 607-616.

Nurse, P. (1975). Genetic control of cell size at cell division in yeast. Nature, London 256, 547551 . 